\title{
Kinerja Karyawan Berbasis Kepemimpinan Dan Motivasi Pada PT. Duta Jaya Putra Persada Mining
}

\author{
Ading Sunarto \\ Dosen Fakultas Ekonomi Universitas Pamulang \\ Email :dosen02153@unpam.ac.id
}

\begin{abstract}
ABSTRAK
Tujuan pada penelitian ini adalah untuk mengetahui pengaruh kepemimpinan dan motivasi terhadap kinerja karyawan pada PT. Duta Jaya Persada Mining.

Metode yang digunakan yaitu penelitian asosiatif serta menggunakan instrument questioner yang masing-masing variable memiliki 8 pernyataan dengan jumlah populasi sekaligus dijadikan sampel sebanyak 50 responden atau menggunakan sampel jenuh. Analisis data yang digunakan menggunakan regresi linear dengan bantuan software SPSS 25.

Hasilnya pengolahan data menunjukkan: 1) Kepemimpinan (X1), berpengaruh positif dan signifikan terhadap Kinerja (Y) di PT. Duta Jaya Persada Mining yang dibuktikan dengan kontribusi pengaruh sebesar 44,3\% dengan pengujian hipotesis diperoleh $\mathrm{t}$ hitung $>\mathrm{t}$ table $(6,180>2,011)$. Motivasi (X2), berpengaruh positif dan signifikan terhadap Kinerja (Y) di PT. Duta Jaya Persada Mining yang dibuktikan dengan kontribusi pengaruh sebesar 40,32\% dengan pengujian hipotesis diperoleh $t$ hitung $>t$ table $(5,685>2,011)$. Dari hasil olah data tersebut perusahaan sebaiknya lebih meningkatkan kepemimpinan dan integritas karyawannya untuk meningkatkan kinerja karyawannya.
\end{abstract}

\section{Kata Kunci: Kepemimpinan, Motivasi Dan Kinerja Karyawan.}




\section{PENDAHULUAN}

Pada hakikatnya, SDM berupa manusia yang dipekerjakan di sebuah organisasi sebagai penggerak, pemikir dan perencana untuk mencapai tujuan organisasi itu. Dewasa ini, perkembangan terbaru memandang karyawan bukan sebagai sumber daya belaka, melainkan lebih berupa modal atau aset bagi institusi atau organisasi. Karena itu kemudian muncullah istilah baru di luar H.R. (Human Resources), yaitu H.C. atau Human Capital. Pengertian SDM dapat dibagi menjadi dua, yaitu pengertian mikro dan makro."Pengertian SDM secara mikro adalah individu yang bekerja dan menjadi anggota suatu perusahaan atau institusi dan biasa disebut sebagai pegawai, buruh, karyawan, pekerja, tenaga kerja dan lain sebagainya."Sedangkan pengertian SDM secara makro adalah penduduk suatu negara yang sudah memasuki usia angkatan kerja, baik yang belum bekerja maupun yang sudah bekerja.

Menurut Sutrisno (2016:3), sumber daya manusia merupakan satu-satunya sumber daya yang memiliki akan perasaan, keinginan, keterampilan, pengetahuan, dorongan, daya, dan karya (rasio, rasa, dan karsa) semua potensi SDM tersebut berpengaruh terhadap upaya organisasi dalam mencapai tujuan. Sementara menurut Menurut Nawawi dalam Gaol (2014:44), Sumber Daya Manusia adalah orang yang bekerja dan berfungsi sebagai aset organisasi/perusahaan yang dapat dihitung jumlahnya (kuantitatif), dan SDM merupakan potensi yang menjadi penggerak organisasi. Manajemen sumber daya manusia merupakan bidang keilmuan yang menitikberatkan pada permasalahan manusia yang mempunyai kedudukan yang utamadalam setiap instansi dan organisasi. Tanpa orang-orang yang memiliki keahlian dan kompetensi maka mustahil bagi perusahaan untuk mencapai tujuannya, sumberdaya ini lah yang membuat sumber daya lain dapat berjalan.

PT.Duta Jaya Putra Persada Mining merupakan perusahaan swasta yang bergerak dibidang Drilling kontraktor yang berpusat di wilayah Tangerang selatan. PT. Duta Jaya Putra Persada Mining merupakan salah satu perusahaan kontruksi yang menyediakan jasa pelayanan pengeboran. Dengan demikian tidak dapat dipungkiri didukung oleh banyaknya karyawan dalam PT.Duta Jaya Putra Persada Mining. Kesejahteraan dan kualitas karyawan menjadi salah satu prioritas PT.Duta Jaya Putra Persada Mining untuk tetap bertahan dalam persaingan pasar dunia.

Pemimpin baik merupakan seorang pemimpin yang dapat mencapai visi dan misi perusahaannya serta menjadikan perusahaannya menjadi perusahaan hebat dan bisa bersaing sehat dalam dunia bisnis dan tentunya memperhatikan kemakmuran karyawannya."Menurut Rivai (2014:42), Gaya Kepemimpinan adalah"sekumpulan ciri yang digunakan pimpinan untuk mempengaruhi bawahan agar sasaran organisasi tercapai atau dapat pula dikatakan bahwa gaya kepemimpinan adalah pola perilaku dan strategi yang disukai dan sering diterapkan oleh seorang pemimpin." 
Hasil observasi menunjukkan bahwa pada saat karyawan sedang dalam masalah, pemimpin perusahaan jarang meluangkan waktunya untuk mendengarkan keluh kesah bawahannya. Pemimpin memperlakukan anak buahnya dengan cara yang sama namun kurang dalam mengatur pola kerjanya dan belum maksimal.

Menurut Irham Fahmi (2016:190), motivasi merupakan aktivitas perilaku yang bekerja dalam usaha memenuhi kebutuhankebutuhan yang diinginkan." Motivasi kerja juga merupakan unsur yang yang harus diperhatikan didalam kepegawaian sebuah perusahaan, yang artinya bahwa karyawan harus memiliki motivasi dalam bekerja. Karyawan yang mempunyai motivasi kerja baik pastinya akan melaksanakan pekerjaannya dengan sungguh-sungguh dengan mengerahkan semua kompetensi yang dimilikinya dalam menyelesaikan semua pekerjannya.

Dari hasil studi pendahuluan yang sudah dilakukan didapatkan informasi bahwa minimnya tingkat inisiatif dan kreativitas pegawai mengindikasikan bahwa motivasi karyawan masih rendah. Motivasi adalah hal yang melatarbelakangi karyawan untuk melakukan tujuan tertentu. Perlilaku masing-masing individu merupakan cerminan yang paling sederhana dalam memotivasi. Supaya perilaku karyawan sesuai dengan visi dan misi organisasi, maka perlu adanya perpaduan antara motivasi akan pemenuhan kesejahterahan mereka sendiri dan permintaan perusahaan.

Menurut Barnawi dan Arifin (2012:12), "kinerja adalah hasil kerja yang dicapai oleh seseorang atau kelompok orang dalam suatu organisasi, sesuai dengan wewenang dan tanggung jawab masing-masing dalam mencapai upaya mencapai tujuan organisasi bersangkutan secara legal, tidak melanggar hukum, dan sesuai dengan moral maupun etika". Sementara menurut Menurut Mangkunegara (2013:67), "kinerja berasal dari kata Job Performance atau Actual Performance (prestasi kerja atau prestasi sesuangguhnya yang dicapai oleh seseorang)". Sementara menurut Marwansyah (2010:228), kinerja adalah pencapaian atau prestasi seseorang berkenaan dengan tugas-tugas yang dibebankan kepadanya.

Dalam pelaksanaan tugas sehari-hari kedisiplinan sering menjadi kendala dalam sebuah organisasi, rendahnya kedisiplinan menjadi persoalan yang berulangulang terjadi. Dari hasil prariset yang penulis lakukan, berikut ini ketimpangan yang terjadi dimana di saat perusahaan sedang menggalakkan program kinerja yang berdayaguna namun justru pada perusahaan ini disiplin kerja menunjukkan trend yang kurang baik. Hal ini dapat dilihat dari data Kehadiran karyawan PT. Duta Jaya putra Persada Mining dari bulan Oktober 2018 sampai dengan bulan September 2019 berikut ini : 
Tabel 1

Total Absensi Karyawan PT. Duta Jaya Putra Persada Mining Periode Oktober 2018 - September 2019

\begin{tabular}{|c|c|c|c|c|c|}
\hline Bulan & $\begin{array}{c}\text { Jumlah } \\
\text { Karyawan }\end{array}$ & Sakit & Cuti & $\begin{array}{c}\text { Telat Tanpa } \\
\text { Keterangan }\end{array}$ & $\begin{array}{c}\text { Telat Dengan } \\
\text { Keterangan }\end{array}$ \\
\hline Oktober 2018 & 50 & 5 & 3 & 7 & 4 \\
\hline November 2018 & 50 & 4 & 4 & 5 & 7 \\
\hline Desember 2018 & 50 & 3 & 2 & 3 & 5 \\
\hline Januari 2019 & 50 & 5 & 3 & 7 & 5 \\
\hline Februari 2019 & 50 & 6 & 7 & 7 & 8 \\
\hline Maret 2019 & 50 & 6 & 6 & 6 & 6 \\
\hline April 2019 & 50 & 7 & 6 & 8 & 7 \\
\hline Mei 2019 & 50 & 3 & 7 & 7 & 6 \\
\hline Juni 2019 & 50 & 7 & 3 & 7 & 7 \\
\hline Juli 2019 & 50 & 5 & 2 & 4 & 8 \\
\hline Agustus 2019 & 50 & 6 & 5 & 6 & $\mathbf{7 9}$ \\
\hline September 2019 & 50 & 4 & 6 & $\mathbf{7 4}$ & \\
\hline Jumlah & & $\mathbf{6 1}$ & $\mathbf{5 4}$ & $\mathbf{7 4}$ & \\
\hline
\end{tabular}

Sumber : HRD PT. Duta Jaya Putra Persada Mining 2019

Berdasarkan dari data tabel 1.1 diatas, menunjukkan bahwa persentase kehadiran karyawan pada bulan Oktober 2018 sampai dengan September 2019 secara keseluruhan dalam kondisi yang kurang baik, dimana dari keseluruhan karyawan baik yang datang terlambat, ijin, tanpa ijin, maupun pulang lebih awal menunjukkan trend yang meningkat, hal ini mengindikasikan masih banyaknya karyawan yang kurang disiplin kerjanya.

Berdasarkan uraian diatas maka judul penelitian yang penulis ingin sampaikan lebih dalam yaitu: "Kinerja Karyawan Berbasis Kepemimpinan Dan Motivasi Study Pada PT. Duta Jaya Putra Persada Mining"

\section{METODE PENELITIAN}

Jenis penelitian yang digunakan adalah dengan menggunakan metode penelitian kuantitatif yang selanjutnya diolah dengan metode statistika menggunakan SPSS Versi 25. Penelitian ini dilaksanakan di PT. Duta Jaya Putra Persada Mining yang beralamat di Jl. Cirendeu Raya No.17 Rt.001/06, Ciputat Timur, Tangerang Selatan. Teknik pengambilan sampel yang digunakan adalah teknik sample jenuh berjumlah 50 dari seluruh populasi. Pengujian data digunakan uji instrumen, uji regresi, uji koefisien determinasi dan uji hipotesis dengan uji t dan uji $\mathrm{F}$.

\section{HASIL PENELITIAN DAN PEMBAHASAN}

\section{A. Hasil Analisis Deskriptif}

1. Variabel Kepemimpinan (X1)

Presentasi Kepemimpinan PT. Duta Jaya Putra Persada Mining dengan sampel 50 karyawan mendapatkan response yang baik, berdasarkan response jawaban karyawan dari 8 pernyataan, diperoleh rata-rata skor sebesar 3,89 termasuk pada rentang skala 3,40-4,19 dengan kriteria baik, jumlah responden yang menjawab sangat setuju dan setuju mencapai $64,75 \%$ dan jumlah responden yang menjawab ragu-ragu, tidak setuju dan sangat tidak setuju mencapai $35,25 \%$ 
2. Variabel Motivasi (X2)

Presentasi motivasi PT. Duta Jaya Putra Persada Mining mendapat respon yang cukup baik, hal ini dapat dilihat dari jawaban yang telah menjawab 8 pernyataan tentang variabel Motivasi, diperoleh rata-rata skor sebesar 4,04 termasuk pada rentang skala 3,40-4,19 dengan kriteria baik, jumlah responden yang menjawab sangat setuju dan setuju mencapai $65,75 \%$ dan jumlah responden yang menjawab ragu-ragu, tidak setuju dan sangat tidak setuju mencapai $34,25 \%$

\section{Variabel Kinerja (Y)}

Presentasi Kinerja PT. Duta

Jaya Putra Persada Mining mendapat respon yang baik dari responden, hal ini dapat dilihat dari jawaban yang telah menjawab 8 pernyataan tentang variabel kinerja, diperoleh rata-rata skor sebesar 4,04 termasuk pada rentang skala 3,40-4,19 dengan kriteria baik, jumlah responden yang menjawab sangat setuju dan setuju mencapai $68 \%$ dan jumlah responden yang menjawab raguragu, tidak setuju dan sangat tidak setuju mencapai $32 \%$

\section{B. Hasil Uji Kualitas Data}

Kualitas suatu data yang sudah diperoleh dari instrument di evaluasi melalui uji validitas dan uji reliabiltas untuk mengetahui akurasi dari setiap instrument penelitian.

1. Hasil Uji Validitas

Validitas instrumen

dalam penelitian ini ditentukan dengan mengkorelasikan antara skor yang diperoleh setiap butir pernyataan dengan skor total. Validitas adalah suatu ukuran yang menunjukkan tingkatantingkatan kevalidan atau kesahihan, sebuah instrumen dikatakan valid apabila mampu mengukur apa yang diinginkan dalam mengungkap data dari variabel yang diteliti secara cermat penilaian uji validitasnya adalah :

a) Apabila $r$ hitung $>r$ tabel 0,279 (taraf signifikan 5\%) maka dikatakan valid

b) Apabila $\mathrm{r}$ hitung $<\mathrm{r}$ tabel 0,279 (taraf signifikan 5\%) maka dikatakan tidak valid.

Nilai $r$ tabel di dapat dengan ketentuan :

$\begin{array}{ll}\text { Sampel } & =50 \\ \text { DK }(\text { derajat Kebebasan }) & =\mathrm{n}-2 \\ \text { Tingkat Kepercayaan } & =95 \% \\ \text { Tingkat Kesalahan } & =5 \% \\ \mathrm{~T} \text { tabel }(\alpha, \mathrm{n}-2) & =5 \%, \\ 48(\text { tabel distribusi R) } & \\ \mathrm{T} \text { tabel }(5 \%, 48) & =0,279\end{array}$

2. Hasil Uji Reliabilitas

Uji reliabilitas adalah suatu indeks yang menunjukan sejauh mana hasil suatu pengukuran dapat dipercaya atau handal sebagai alat ukur variabel. Pada penelitian ini untuk mencari reliabilitas instrumen menggunakan rumus Cronbach Alpha. Berikut table hasil reliabilitas instrument, sbb:

Tabel 2 Hasil Uji Reliabilitas Data

\begin{tabular}{|c|c|c|c|}
\hline No & Variabel & $\begin{array}{c}\text { Cronbach } \\
\text { Alpha }\end{array}$ & Kesimpulan \\
\hline 1 & $\begin{array}{c}\text { Kepemimpinan } \\
(\mathrm{X} 1)\end{array}$ & 0,678 & Reliabel \\
\hline 2 & Motivasi (X2) & 0,691 & Reliabel \\
\hline 3 & Kinerja (Y) & 0,676 & Reliabel \\
\hline
\end{tabular}

Sumber: Data Olahan SPSS 25 (2019) 


\section{Pengujian Asumsi Klasik}

\section{Hasil Uji Normalitas}

Uji normalitas untuk menguji distribusi data yang akan dianalisis menyebar normal. Uji normalitas dimaksudkan untuk menguji apakah data yang digunakan dalam penelitian memiliki distribusi normal baik secara multivarian maupun univarian. Berikut grafik hasil normalitas instrument yang digunakan.

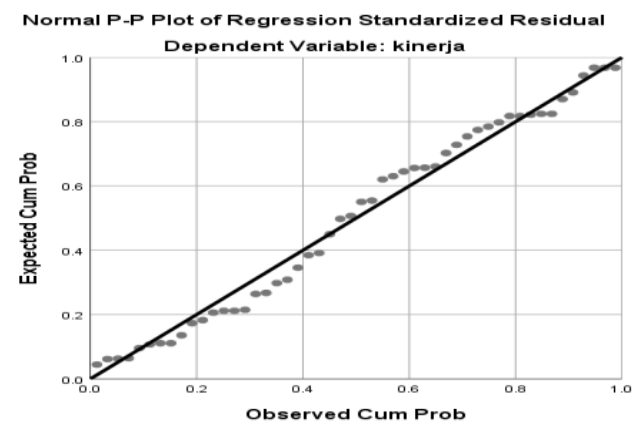

Sumber: Data primer yang diolah dengan SPSS versi 25, tahun 2019

Gambar 1

Grafik Normal P-P plot

Kepemimpinan, Motivasi, dan

Disiplin Terhadap Kinerja

Dari grafik Normal PP-Plot dapat terlihat pola penyebaran data dimana yang berbentuk titik atau lingkaran kecil menyebar mengikuti garis lurus diagonal disekitar diagram. Maka dapat disimpulkan bahwa data residu dari variabel independen Kepemimpinan (X1) dan Motivasi (X2) yang diteliti adalah data yang berdistribusi normal. Dengan demikian uji normalitas menunjukkan terpenuhi asumsi Normalitas.

\section{Uji Multikolinieritas}

Uji multikolinearitas dilakukan untuk mengetahui apakah terdapat korelasi atau hubungan yang kuat antar variabel-variabel independen dalam model persamaan regresi. Model regresi yang baik sebaiknya tidak terjadi korelasi antar variabel bebas. Sebagai dasar acuan untuk melihat nilai korelasi antar variabel bebas dan juga melihat Tolerance Value dan Variance Inflation Factor (VIF) dapat ditentukan hipotesa yaitu:

$\mathrm{H}_{\mathrm{o}}$ : Tidak terdapat multikolinearitas antar variabel bebas dalam model regresi, bila nilai korelasi antar variabel bebas $<95 \%$, atau nilai toleransi $>0,10$ persen dan nilai VIF $<10$.

$\mathrm{H}_{\mathrm{a}}$ :Terdapat multikolinearitas antar variabel bebas dalam model regresi, bila nilai korelasi antar variabel bebas > $95 \%$, atau nilai toleransi < 0.10 persen dan nilai VIF > 10.

Hasil output uji multikolinearitas adalah sebagai berikut :

\section{Tabel 3 Uji Multikolinearitas}

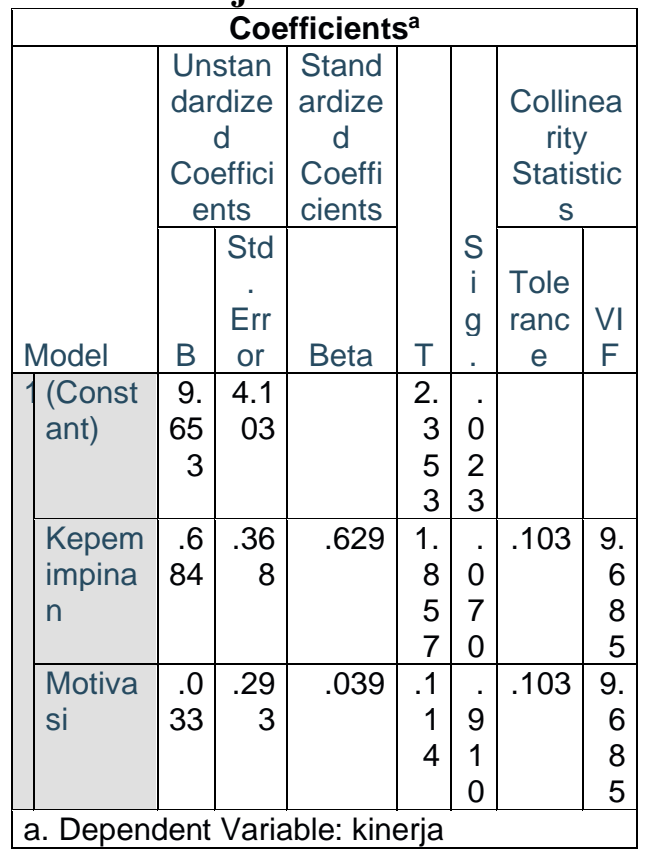


Sumber: Data primer yang diolah dengan SPSS versi 25, tahun 2019.

Dari tabel diatas maka dapat dilihat:

(1)Kepemimpinan (XI) memiliki nilai Tolerance Value : 0,103 $>0,01$ atau VIF : 9,685 < 10.00 .

(2)Motivasi (X2) memiliki nilai Tolerance Value : 0,103>0,01 atau VIF : 9,685 < 10.00 .

Berdasarkan hasil tersebut maka dalam model regresi tidak terjadi multikolineritas yang sempurna antara variabel-variabel bebas, yaitu kepemimpinan dan motivasi, karena nilai VIF $9,685<10$ dan nilai tolerance $0,103>0,1$.

Untuk mengetahui apakah varian yang sama dimiliki oleh variable pengganggu atau tidak, dapat mengetahuinya dengan melakukan uji Heteroskedastisitas.Dalam model regresi tidak boleh ada suatu gejala Heteroskedastisitas agar dapat

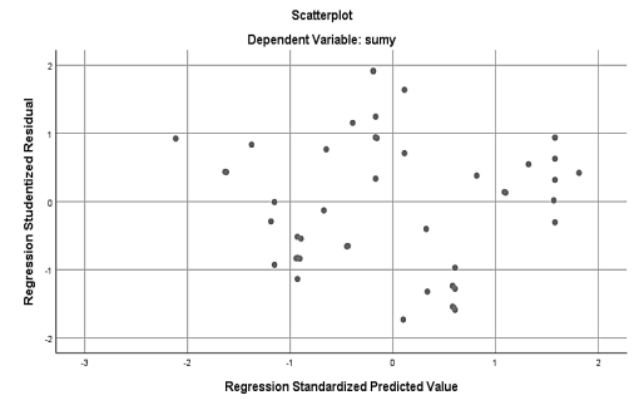

memenuhi persyaratan.

Sumber : Hasil yang diolah dengan SPSS 25

\section{Gambar 2}

Hasil Uji Heteroskedastisitas

Dari gambar scatterplot diatas, terlihat bahwa titik-titik menyebar secara acak, baik di bagian atas angka 0 atau bagian bawah angka 0 dari sumbu vertikal atau sumbu Y. Dengan demikian dapat disimpulkan bahwa tidak terjadi heteroskedastisitas dalam model regresi ini.

\section{Uji Hipotesis}

Menurut Sugiyono (2009:70) menyatakan bahwa hipotesis merupakan jawaban sementara terhadap rumusan masalah penelitian.

\section{Hasil Pengujian Hipotesis Pertama (X1 ke Y)}

\section{a. Uji t}

Dalam penelitian ini digunakan kriteria signifikansi $5 \% \quad(0,05) \quad$ dengan membandingkan $t_{\text {hitung dengan }}$ $t_{\text {tabel }}$ yaitu sebagai berikut :

Jika $t_{\text {hitung }}<\mathrm{t}_{\text {tabel }}$ : berarti Ho diterima dan $\mathrm{H}_{1}$ ditolak $(\alpha=$ $5 \%$ )

Jika $t_{\text {hitung }}>t_{\text {tabel }}:$ berarti Ho ditolak dan $\mathrm{H}_{1}$ diterima $(\alpha=$ $5 \%$ )

Besarnya $t_{\text {tabel }}$ dicari dengan menggunakan rumus :

$\mathrm{Df}=(\mathrm{n}-2)$, maka diperoleh $(50-$

2) $=48$, sehingga $t_{\text {tabel }}=2,011$

\section{Tabel 4}

\section{Hasil Uji t Parsial Hipotesis}

Pertama

\begin{tabular}{|c|c|c|c|c|c|}
\hline \multicolumn{6}{|c|}{ Coefficients $^{a}$} \\
\hline \multirow[b]{2}{*}{ Model } & $\begin{array}{r}\text { Uns } \\
\text { ard } \\
\text { Coe } \\
n\end{array}$ & $\begin{array}{l}\text { and } \\
\text { ed } \\
\text { icie }\end{array}$ & $\begin{array}{c}\text { Standa } \\
\text { rdized } \\
\text { Coeffici } \\
\text { ents }\end{array}$ & & \\
\hline & B & $\begin{array}{l}\text { Std } \\
\text { Err } \\
\text { or }\end{array}$ & Beta & $\mathrm{T}$ & $\begin{array}{l}\text { Si } \\
\text { g. }\end{array}$ \\
\hline 1 (Consta & $\begin{array}{r}9.4 \\
69\end{array}$ & $\begin{array}{r}3.7 \\
36\end{array}$ & & $\begin{array}{r}2 . \\
53 \\
4\end{array}$ & $\begin{array}{r}.0 \\
1 \\
5\end{array}$ \\
\hline $\begin{array}{l}\text { Kepemi } \\
\text { mpinan }\end{array}$ & $\begin{array}{r}.72 \\
4\end{array}$ & $\begin{array}{r}.11 \\
7\end{array}$ & .666 & $\begin{array}{r}6 . \\
18 \\
0\end{array}$ & $\begin{array}{l}.0 \\
0 \\
0\end{array}$ \\
\hline
\end{tabular}

a. Dependent Variable: $y$

Sumber : Hasil yang diolah dengan SPSS 25 


\section{b. Uji Koefisen Korelasi}

Hasil korelasi antara Kepemimpinan $\left(\mathrm{X}_{1}\right)$ terhadap kinerka karyawan (Y) dapat dilihat pada table dibawah ini :

Tabel 5

Hasil Analisis Regresi Linear

Hipotesis Pertama

\begin{tabular}{|l|l|r|r|}
\hline \multicolumn{3}{|c|}{ Correlations } \\
\hline \multirow{2}{|c|}{$x 1$} & \multicolumn{1}{|c|}{$x 1$} & \multicolumn{1}{|c|}{$\mathrm{Y}$} \\
\hline & $\begin{array}{l}\text { Pearson } \\
\text { Correlation }\end{array}$ & 1 & $.666^{* *}$ \\
\cline { 2 - 4 } & Sig. (2-tailed) & & .000 \\
\cline { 2 - 4 } & $\mathrm{N}$ & 50 & 50 \\
\hline $\mathrm{Y}$ & $\begin{array}{l}\text { Pearson } \\
\text { Correlation }\end{array}$ & $.666^{* *}$ & 1 \\
\cline { 2 - 4 } & Sig. (2-tailed) & .000 & \\
\cline { 2 - 4 } & $\mathrm{N}$ & 50 & 50 \\
\hline \multirow{2}{*}{} & & \\
\hline
\end{tabular}

**. Correlation is significant at the 0.01 level (2-tailed).

Sumber: Data primer yang diolah dengan SPSS versi 25, tahun 2019

Berdasarkan hasil

korelasi pada table di atas, maka diperoleh nilai koefisien korelasi sebesar 0,666, artinya variabel Kepemimpinan $\left(\mathrm{X}_{1}\right)$ memiliki tingkat hubungan yang kuat terhadap variabel kinerja karyawan (Y).

c. Koefisien Determinasi (RSquare)

\section{Tabel 6}

Koefisien Determinasi Hipotesis

Pertama

\begin{tabular}{|c|c|c|c|c|}
\hline \multicolumn{5}{|c|}{ Model Summary } \\
\hline $\begin{array}{l}\text { Mod } \\
\text { el }\end{array}$ & $R$ & $\begin{array}{c}\mathrm{R} \\
\text { Squar } \\
\mathrm{e}\end{array}$ & $\begin{array}{l}\text { Adjuste } \\
d R \\
\text { Square }\end{array}$ & $\begin{array}{l}\text { Std. } \\
\text { Error of } \\
\text { the } \\
\text { Estimat } \\
e\end{array}$ \\
\hline 1 & $\begin{array}{r}.666 \\
\mathrm{a}\end{array}$ & .443 & .432 & 3.3019 \\
\hline
\end{tabular}

a. Predictors: (Constant), kepemimpinan

Sumber: Data primer yang diolah dengan SPSS versi 25, tahun 2019

Berdasarkan tabel di atas, diperoleh nilai $R$-Square (koefisien determinasi) sebesar 0,443 maka dapat disimpulkan bahwa besarnya pengaruh variabel kepemimpinan $\left(\mathrm{X}_{1}\right)$ terhadap variabel kinerja karyawan (Y) sebesar 44,3\% sedangkan sisanya $55,7 \%$ dipengaruhi faktor lain.

\section{Hasil Pengujian Hipotesis} Kedua (X2 ke Y)

a. Uji t

Tabel 7

Hasil Uji t Parsial Hipotesis Kedua

\begin{tabular}{|c|c|c|c|c|c|}
\hline \multicolumn{6}{|c|}{ Coefficients $^{a}$} \\
\hline \multirow[b]{2}{*}{ Model } & $\begin{array}{r}\text { Unst } \\
\text { rdi } \\
\text { Coef } \\
t\end{array}$ & $\begin{array}{l}\text { anda } \\
\text { ed } \\
\text { icien }\end{array}$ & $\begin{array}{l}\text { Standar } \\
\text { dized } \\
\text { Coeffici } \\
\text { ents }\end{array}$ & & \\
\hline & B & $\begin{array}{c}\text { Std. } \\
\text { Erro } \\
r \\
\end{array}$ & Beta & T & $\begin{array}{l}\text { Si } \\
\text { g. }\end{array}$ \\
\hline $1 \begin{array}{l}\text { (Const } \\
\text { ant) }\end{array}$ & $\begin{array}{r}14.7 \\
11\end{array}$ & $\begin{array}{r}3.14 \\
5\end{array}$ & & $\begin{array}{r}4.6 \\
77\end{array}$ & $\begin{array}{l}.0 \\
00\end{array}$ \\
\hline$x 2$ & .549 & .097 & .634 & $\begin{array}{r}5.6 \\
85\end{array}$ & $\begin{array}{r}.0 \\
00\end{array}$ \\
\hline
\end{tabular}

a. Dependent Variable: $y$

Sumber: Data primer yang diolah dengan SPSS versi 25, tahun 2019

b. Uji Koefisien Korelasi

Hasil korelasi antara Motivasi Kerja $\left(\mathrm{X}_{2}\right)$ terhadap kinerka karyawan (Y) dapat dilihat pada table dibawah ini :

\section{Tabel 8}

\section{Hasil Analisis Regresi Linear}

Hipotesis Kedua

\begin{tabular}{|c|c|c|c|}
\hline \multicolumn{4}{|c|}{ Correlations } \\
\hline & & $\mathrm{x} 1$ & $\mathrm{Y}$ \\
\hline \multirow[t]{3}{*}{$x 2$} & $\begin{array}{l}\text { Pearson } \\
\text { Correlation }\end{array}$ & 1 & $.634^{* *}$ \\
\hline & Sig. (2-tailed) & & .000 \\
\hline & $\mathrm{N}$ & 50 & 50 \\
\hline \multirow[t]{3}{*}{$\bar{Y}$} & $\begin{array}{l}\text { Pearson } \\
\text { Correlation }\end{array}$ & $.634^{* *}$ & \\
\hline & Sig. (2-tailed) & .000 & \\
\hline & $\mathrm{N}$ & 50 & 50 \\
\hline
\end{tabular}


Sumber: Data primer yang diolah dengan SPSS versi 25, tahun 2019

Berdasarkan hasil korelasi pada table di atas, maka diperoleh nilai koefisien korelasi sebesar 0,634, artinya variabel motivasi Kerja (X2) memiliki tingkat hubungan yang kuat terhadap variabel kinerja karyawan (Y).

c. Koefisien Determinasi (RSquare)

Tabel 9

Koefisien Determinasi Hipotesis Kedua

\begin{tabular}{|c|c|c|c|c|}
\hline \multicolumn{5}{|c|}{ Model Summary } \\
\hline $\begin{array}{l}\text { Mod } \\
\text { el }\end{array}$ & $\mathrm{R}$ & $\begin{array}{c}\mathrm{R} \\
\text { Squar } \\
\mathrm{e}\end{array}$ & $\begin{array}{c}\text { Adjuste } \\
\text { d R } \\
\text { Square }\end{array}$ & $\begin{array}{c}\text { Std. } \\
\text { Error of } \\
\text { the } \\
\text { Estimat } \\
\text { e }\end{array}$ \\
\hline 1 & $\begin{array}{r}.634 \\
a\end{array}$ & .402 & .390 & 3.4205 \\
\hline a. $P$ & 0 & on & t), mo & \\
\hline
\end{tabular}

Sumber: Data primer yang diolah dengan SPSS versi 25, tahun 2019

Berdasarkan tabel di atas, diperoleh nilai $R$-Square (koefisien determinasi) sebesar 0,789 maka dapat disimpulkan bahwa besarnya pengaruh variabel motivasi $\left(\mathrm{X}_{2}\right)$ terhadap variabel kinerja karyawan $(\mathrm{Y})$ sebesar 40,2\% sedangkan sisanya $59,8 \%$ dipengaruhi faktor lain

\section{Hasil Pengujian Hipotesis Ke-} Tiga ( $X_{1}$ dan $X_{2}$ ke $Y$ )

\section{a. Hasil Regresi Berganda Hipotesis ke-tiga}

Kepemimpinan dan

Motivasi berpengaruh pada Kinerja Karyawan pada PT. Duta Jaya Putra Persada Mining secara simultan, Dan untuk dapat melihat apakah variable Kepemimpinan $\left(\mathrm{X}_{1}\right)$ dan Motivasi $\left(\mathrm{X}_{2}\right)$ memberikan pengaruh yang positif pada variable Kinerja Karyawan (Y) pada PT. Duta Jaya Putra Persada Mining dapat dinyatakan oleh uji regresi berganda hipotesis ke-tiga sebagai berikut :

Tabel 10

Hasil pengolahan Regresi

Berganda Variabel ( $X_{1}$ dan $\left.X_{2}\right)$

\begin{tabular}{|c|c|c|c|c|c|}
\hline \multicolumn{6}{|c|}{ Coefficients $^{a}$} \\
\hline \multirow[b]{2}{*}{ Model } & \multicolumn{2}{|c|}{$\begin{array}{l}\text { Unstanda } \\
\text { rdized } \\
\text { Coefficien } \\
\text { ts }\end{array}$} & \multirow{2}{*}{$\begin{array}{c}\begin{array}{c}\text { Standar } \\
\text { dized } \\
\text { Coeffici } \\
\text { ents }\end{array} \\
\text { Beta }\end{array}$} & \multirow[b]{2}{*}{$\mathrm{t}$} & \multirow[b]{2}{*}{$\begin{array}{l}\text { Si } \\
\text { g. }\end{array}$} \\
\hline & B & $\begin{array}{c}\text { Std. } \\
\text { Erro } \\
r\end{array}$ & & & \\
\hline 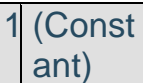 & $\begin{array}{r}9.6 \\
53\end{array}$ & $\begin{array}{r}4.10 \\
3\end{array}$ & & $\begin{array}{r}2.3 \\
53\end{array}$ & $\begin{array}{l}.0 \\
23\end{array}$ \\
\hline$x 1$ & $\begin{array}{r}.68 \\
4\end{array}$ & .368 & .629 & $\begin{array}{r}1.8 \\
57\end{array}$ & $\begin{array}{l}.0 \\
70\end{array}$ \\
\hline$x 2$ & $\begin{array}{r}.03 \\
3\end{array}$ & .293 & .039 & $\begin{array}{r}.11 \\
4\end{array}$ & $\begin{array}{l}.9 \\
10\end{array}$ \\
\hline Depe & & ri & & & \\
\hline
\end{tabular}

Sumber: Data primer yang diolah dengan SPSS versi 25, tahun 2019

Dari table diatas, maka persamaan regresi yang terbentuk pada uji regresi adalah $Y=9,653+0,684 X_{1}+0,033 X_{2}+e$

b. Koefisien Determinasi ( $R$ Square)

Variabel bebas

Kepemimpinan dan Motivasi terhadap kinerja dapat diukur besar pengaruhnya dengan menggunakan nilai koefisien determinasi $\quad\left(\mathrm{R}^{2}\right) . \quad$ Nilai koefisien determinasi $\left(\mathrm{R}^{2}\right)$ digunakan untuk mengukur besarnya pengaruh variabel Kepemimpinan dan Motivasi terhadap kinerja karyawan pada 
PT. Duta Jaya Putra Persada Mining

Tabel 11

Koefisien Determinasi Hipotesis Ketiga

\begin{tabular}{|c|c|c|c|c|}
\hline \multicolumn{5}{|c|}{ Model Summary } \\
\hline $\begin{array}{l}\text { Mod } \\
\text { el }\end{array}$ & $R$ & $\begin{array}{c}\text { R } \\
\text { Squar } \\
\text { e }\end{array}$ & $\begin{array}{c}\text { Adjuste } \\
\text { d R } \\
\text { Square }\end{array}$ & $\begin{array}{l}\text { Std. } \\
\text { Error of } \\
\text { the } \\
\text { Estimat } \\
\text { e }\end{array}$ \\
\hline 1 & $\begin{array}{r}.666 \\
a\end{array}$ & .443 & .420 & $\begin{array}{r}3.3364 \\
6\end{array}$ \\
\hline
\end{tabular}

a. Predictors: (Constant), motivasi, kepemimpinan

Sumber: Data primer yang diolah dengan SPSS versi 25, tahun 2019

Berdasarkan tabel di atas, diperoleh nilai $R$-Square (koefisien determinasi) sebesar 0,443 maka dapat disimpulkan bahwa variabel kepemimpinan dan motivasi berpengaruh terhadap variabel kinerja karyawan sebesar 44,3\% sedangkan sisanya $\quad 55,7 \quad \%$ dipengaruhi faktor lain.

c. Uji Serempak Hipotesis Ketiga

Tabel 12

Hasil Uji F Simultan Hipotesis

Ketiga

\begin{tabular}{|l|r|r|r|r|r|}
\hline \multicolumn{7}{|c|}{ ANOVA $^{\mathrm{a}}$} \\
\hline & $\begin{array}{c}\text { Sum } \\
\text { of } \\
\text { Squa } \\
\text { Model }\end{array}$ & $\begin{array}{c}\text { Mean } \\
\text { res }\end{array}$ & $\begin{array}{c}\text { Squa } \\
\text { Sq }\end{array}$ & F & Sig \\
\hline 1 Regres & 416.5 & 2 & 208.2 & 18.7 & .00 \\
sion & 76 & & 88 & 11 & $0^{\mathrm{b}}$ \\
\hline Residu & $\begin{array}{r}523.2 \\
\text { al }\end{array}$ & 4 & 11.13 & & \\
\hline Total & 939.7 & 7 & 2 & & \\
\hline & 80 & 9 & & & \\
\hline
\end{tabular}

a. Dependent Variable: kinerja

b. Predictors: (Constant), motivasi, kepemimpinan

Sumber: Data primer yang diolah dengan SPSS versi 25, tahun 2019
Berdasarkan tabel diatas diperoleh nilai $\mathrm{F}_{\text {hitung }}=18,711>$ 3,20 atau ( $\left.F_{\text {hitung }}>F_{\text {tabel }}\right)$, hal tersebut juga diperkuat dengan signifikansi $0,000<0,05$. Dengan demikian Ho ditolak dan Ha diterima. Artinya terdapat pengaruh positif dan signifikan secara simultan antara kepemimpinan dan motivasi terhadap kinerja karyawan pada pada PT. Duta Jaya Putra Persada Mining.

\section{E. Pembahasan}

1. Pengaruh Gaya Kepemimpinan $\left(\mathrm{X}_{1}\right)$ terhadap Kinerja $(\mathrm{Y})$ secara parsial

Berdasarkan hasil statistik dapat diketahui bahwa pengaruh kepemimpinan $\left(\mathrm{X}_{1}\right)$ terhadap kinerja karyawan (Y) adalah 0,443 atau sebesar 44,3\% sedangkan sisanya $55,7 \%$ dipengaruhi oleh faktor lain. Hal ini menunjukkan bahwa kepemimpinan yang baik akan meningkatkan kinerja karyawan. Dari pengujian hipotesis diperoleh $t_{\text {hitung }}>t_{\text {tabel }}$ atau $(6,180>2,011)$ hal itu juga dibuktikan dengan signifikansi $0,000<0,05$. Dengan demikian

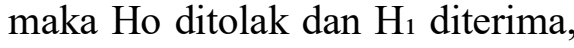
hal ini menunjukkan bahwa terdapat pengaruh yang positif dan signifikan secara parsial antara kepemimpinan terhadap kinerja karyawan pada PT. Duta Jaya Putra Persada Mining.

2. Pengaruh Motivasi $\left(X_{2}\right)$ terhadap Kinerja (Y) secara parsial

Berdasarkan hasil statistik dapat diketahui bahwa pengaruh motivasi $\left(\mathrm{X}_{2}\right)$ terhadap kinerja karyawan (Y) adalah 0,402 atau sebesar $40,2 \%$ sedangkan sisanya 
$59,8 \%$ dipengaruhi oleh faktor lain. Hal ini menunjukkan bahwa motivasi yang baik akan meningkatkan kinerja karyawan. Dari pengujian hipotesis diperoleh $t_{\text {hitung }}>t_{\text {tabel }}$ atau $(5,685>2,011)$ hal itu juga dibuktikan dengan signifikansi $0,000<0,05$. Dengan demikian maka Ho ditolak dan $\mathrm{H}_{1}$ diterima. Hal ini menunjukkan bahwa terdapat pengaruh yang positif dan signifikan secara parsial antara motivasi terhadap kinerja karyawan pada pada PT. Duta Jaya Putra Persada Mining.

3. Pengaruh Kepemimpinan $\left(\mathrm{X}_{1}\right)$ Dan Motivasi $\left(\mathrm{X}_{2}\right)$ terhadap Kinerja (Y) secara simultan

Berdasarkan hasil perhitungan regresi pada tabel diatas, diperoleh persamaan regresinya

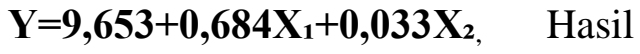
analisis regresi ini menunjukkan koefisien dari variabel kepemimpinan sebesar 0,684 dan variabel motivasi sebesar 0,033. Semuanya bertanda positif artinya semakin baik kepemimpinan dan motivasi kerja maka akan semakin baik pula kinerja karyawan pada PT. Duta Jaya Putra Persada Mining. Sebaliknya, semakin buruk kepemimpinan dan motivasi maka akan semakin rendah kinerja karyawan pada PT. Duta Jaya Putra Persada Mining. Kontribusi pengaruh kepemimpinan dan motivasi kerja adalah sebesar 0,443 atau $44,3 \%$ sedangkan sisanya sebesar $55,7 \%$ dipengaruhi oleh faktor lain. Dari pengujian hipotesis diperoleh menggunakan uji satistik, diperoleh $F_{\text {hitung }}=18,711>3,20$ atau $\left(F_{\text {hitung }}>\right.$ $\left.\mathrm{F}_{\text {tabel}}\right)$ sehingga Ho ditolak dan Hi diterima. Artinya terdapat pengaruh positif dan signifikan secara simultan antara kepemimpinan dan motivasi kerja terhadap kinerja karyawan pada PT. Duta Jaya Putra Persada Mining.

\section{KESIMPULAN DAN SARAN}

\section{A. Kesimpulan}

Penulis melakukan penelitian di PT. Duta Jaya Putra Persada Mining, perusahaan swasta yang bergerak di bidang Drilling kontraktor yang menyediakan jasa pelayanan pengeboran. Berdasarkan hasil pembahasannya penulis memberikan kesimpulan dari hasil penelitian sbb :

1. Kepemimpinan $\left(\mathrm{X}_{1}\right)$ berpengaruh positif dan signifikan terhadap kinerja karyawan (Y) secara parsial di PT. Duta Jaya Putra Persada Mining.

2. Motivasi $\left(\mathrm{X}_{2}\right)$ berpengaruh positif dan signifikan terhadap kinerja karyawan (Y) secara parsial di PT. Duta Jaya Putra Persada Mining.

3. Kepemimpinan $\left(\mathrm{X}_{1}\right)$ dan Motivasi $\left(\mathrm{X}_{2}\right)$ berpengaruh positif dan signifikan terhadap kinerja karyawan (Y) secara parsial di PT. Duta Jaya Putra Persada Mining secara simultan

4. Variabel lain yang belum diteliti didalam penelitian ini harus diperhatikan oleh PT. Duta Jaya Putra Persada Mining, sebab masih banyak variabel lain yang bisa mempengaruhi kinerja karyawan agar visi dan misi perusahaan dapat tercapai.

\section{B. Saran}

Penulis menyampaikan saran kepada PT. Duta Jaya Putra Persada Mining, sebagai berikut :

1. Menyarankan untuk pemimpin di perusahaan lebih peka dan meningkatkan tingkat kepedulian terhadap kebutuhan karyawannya 
agar mereka dapat bekerja lebih baik lagi.

2. Menyarankan agar perusahaan lebih memperhatikan dan meningkatkan kesejahterahan bagi para karyawannya.

3. Menyarankan agar pemberian sanksi atau hukuman bagi karyawan agar diperhatikan kembali, serta harus memberikan pengarahan dan motivasi yang lebih baik lagi.

4. Perusahaan perlu meningkatkan disiplin waktu dan absensi karyawan dalam bekerja, agar target perusahaan dapat tercapai.

5. Perusahaan segera memperbaiki tata ruang di area kerja dengan menjaga kerapihan dan kebersihannya agar lebih nyaman untuk semua karyawan.

\section{DAFTAR PUSTAKA}

Barnawi dan Arifin, M, (2012), Kinerja Guru Profesional, Yogyakarta : Ar-Ruzz Media.

Gaol, CHR. Jimmy L, (2014). A to Z Human Capital (Manajemen Sumber Daya Manusia) Konsep,

Teori, dan Pengembangan dalam Konteks Organisasi Publik dan Bisnis, Jakarta. Gramedia Widiasarana.

Fahmi, Irham, (2016). Manajemen Sumber Daya Manusia Teori dan Aplikasi, Bandung: Alfabeta.

Mangkunegara, Anwar, Prabu, (2013). Manajemen Sumber Daya Manusia Perusahaan, Bandung : Penerbit Remaja Rosdakarya.
Marwansyah, (2010). Manajemen Sumber Daya Manusia, Edisi Kedua, Bandung : Alfabeta.

Rialmi, Z., \& Morsen, M. (2020). Pengaruh Komunikasi Terhadap Kinerja Karyawan PT Utama Metal Abadi. JENIUS, 3(2), 221-227.

Rialmi, Z. (2017). Pengaruh Keadilan Prosedural Yang Diterapkan Kepemimpinan Pegawai Dan Kepuasan Kerja Pegawai Terhadap Kinerja Dari Pegawai BPBD Provinsi Riau. Jurnal Mandiri: Ilmu Pengetahuan, Seni, dan Teknologi, 1(2), 353374.

Rivai, Veithzal, (2014). Manajemen Sumber Daya Manusia Untuk Perusahaan. Jakarta: Raja Grafindo Persada.

Sugiyono, 2009, Metode Penelitian Kuantitatif dan Kualitatif, Bandung : Alfabeta.

Sunarsi, D. (2018). Pengaruh Motivasi Dan Disiplin Terhadap Produktivitas Kerja Karyawan Pada PT. Nadi Suwarna Bumi. Jurnal Semarak, 1(1).

Sunarsi, D. (2020). Panduan Meningkatkan Kinerja Dan Kepuasan Guru. Kota Serang: Desanta Muliavisitama

Sunarsi, D. (2019). Seminar Sumber Daya Manusia. Tangerang Selatan: Unpam Press

Sunarsi, D. (2018). Buku Ajar: Seminar Perencanaan Sumber Daya Manusia. Tangerang Selatan: Asmoro Mediatama

Sutrisno. Edy. (2016). Manajemen Personalia Dan Manajemen Sumber Daya Manusia. Jakarta : Prenada Media Group. 